\title{
The Appraisal of Junior College and
}

\section{College Libraries}

$\mathbf{M}^{\circ}$ OST OF YOU ARE INTERESTED IN CRITERIA for the evaluation of junior college libraries and would like to know the trend of thinking on this subject in the Commission on Colleges and Universities of the North Central Association. Perhaps you hope that some of my remarks tonight may help you in the solution of the immediate problem you face, that of agreeing on national standards for the junior college library which may serve as guides to librarians and other administrators throughout the country. With your indulgence, however, I should prefer to discuss the problem of library evaluation in a somewhat broader framework. Although the junior college library differs in certain important respects from the library in other types of academic institutions and it is appropriate that junior college librarians deal as specifically as possible with their own problems, it is true also that in theory and technique the problem of evaluating a junior college library is part of the larger problem of evaluating any academic library. Once we have decided how best to appraise college libraries in general we shall be well on our way to the solution of the more specialized junior college problem. Therefore my remarks will be rather gen-

Dr. Pattillo is associate director of the Lilly Endowment, Indianapolis. He was formerly associate secretary, Commission on Colleges and Universities, North Central Association. This paper was presented at a meeting of the Junior College Section, ACRL, Chicago, February 1, 1956. eral and afterwards we can discuss the issues as they bear especially on the junior college library.

After some seven years of coping with the practical problems of examining institutions for accrediting purposes, I can testify that the library is one of the most difficult phases of an institution's program to evaluate adequately. This is generally recognized among men who have made many surveys of colleges and universities. In almost every other area of an institution's program informed persons have a reasonably clear notion of what to look at and how to draw conclusions in an evaluation. This is not to say that the appraisal of a faculty, for example, is an easy matter, or that a great deal of refinement in methods is not possible in the future. But, in general, survey specialists are agreed on what is important in judging the competence of a faculty and on the kinds of data and the methods of securing data that are required to do this job. In the area of the library there is no such unanimity. There seem to be serious problems in almost every method of appraising the effectiveness of a college library. Beyond certain very general propositions which would be widely accepted, there is a paucity of constructive thought as to how to proceed in the specific situation. Somehow we need to develop some very different way of looking at the whole problem.

It is helpful to review what has been done in the past. There have been some important changes in the procedures for evaluating college libraries. Here personal experience makes it desirable to refer 
to the policies of the North Central Association. They are reasonably representative of what is being done by other accrediting agencies.

First, consider Standard XI, entitled "Libraries and Laboratories," which set forth the standards for judging college libraries for accrediting purposes in the North Central Association in 1928. That portion of the standard which pertained to libraries read as follows:

The college shall have a live, well-distributed, professionally administered library of at least 8,000 volumes exclusive of public documents, bearing specifically upon the subjects taught and with a definite annual appropriation for the purchase of new books and current periodicals. It is urged that such appropriation be at least $\$ 5.00$ per student registered.

This standard provided something definite for the examiner. If a given college had a library with fewer than 8,000 volumes and if the appropriation for the purchase of new books and current periodicals was less than five dollars per student, the library was unacceptable and the institution would not be worthy of accreditation. The application of such a standard is a fairly simple matter. To be sure, this standard specified that the collection should be live, well distributed, and related to the subjects taught in the institution, and that there should be a professional librarian in charge. The inclusion of these factors in this standard was a change from some of the earlier standards which were almost entirely what are called minimum quantitative standards, but the 1928 standard was probably administered almost entirely on a statistical basis because the statistical parts of the standard were those which stood out.

Then in the early 1930's, following a comprehensive study of institutional evaluation, the North Central Association adopted a radically different philosophy of accrediting. The fundamental proposi- tions of this new philosophy, which were subsequently followed by almost every other accrediting agency, were: An institution should be evaluated in terms of its own avowed purposes. The criteria employed should be primarily qualitative rather than quantitative. An institution would be judged on the basis of the overall picture of strength and weakness it presented rather than on the basis of the application of discrete standards.

The new procedure was set forth in 11 sections which make a small book. The whole procedure became a much more elaborate affair. Gone were the simple yardsticks which could be applied routinely with easily secured data. The evaluation of an institution became almost a research project, so voluminous was the body of information secured and so comprehensive were the criteria employed. In place of a one-paragraph statement on the library, the new Manual of Accrediting had a whole section on the library, consisting of four printed pages. In broad outline, the library criteria were as follows: The first two criteria concerned the holdings of reference books and periodicals. The principle was that an institution should have in its library the works of general and special reference and the periodicals that are generally found in good institutions having similar curricula. The application of these criteria depended on the use of check lists of reference books and periodicals which were regarded as important in institutions of various types. In the use of the check lists, special provision was made for differences in curriculum; that is to say, an institution that offered no courses in astronomy would be exempted from the astronomy section of the lists. The precise measure employed in the application of the criteria was the percentage of books from the selected list which were held by the institution. Each institution was ranked on this item on the basis of norms derived from the actual holdings of the member higher institutions of the asso- 
ciation. There were four sets of norms: one for junior colleges, one for bachelor's degree-granting institutions, one for somewhat more complex institutions usually offering the master's degree, and one for universities. There were some statistical refinements which we need not consider here, but you have a broad outline of the criteria and the way in which they were applied.

After the use of these two measures for about fifteen years, certain significant weaknesses became apparent. First, there was a tendency on the part of librarians to use the check lists as buying guides. It is clear that the lists were originally devised as a fairly systematic sampling device and were never thought of as including all the holdings that any institution would find it desirable to have. Up to a point, the use of the check lists as suggestive of purchases was legitimate, but heavy reliance on them would certainly place an undesirable limitation on the processes for the selection of library materials. This would make selection a much more routine enterprise than it ought to be in any institution.

Secondly, there was the sheer difficulty of keeping the check lists up to date and of assuring that the titles listed were the ones that were most important. Such a list does not take proper account of differences in instructional procedures as well as subject-matter areas in an institution. To use an extreme example, a progressive college such as Sarah Lawrence with its heavy emphasis upon contemporary problems might well need much more extensive holdings of periodicals, particularly in the social sciences, than would an institution like St. John's where the curriculum is heavily weighted in the direction of classical materials. Any kind of standard list introduces a rigidity which cannot be defended if one holds the view that diversity is desirable in American higher education.

The result of all this was that in 1949 a committee of distinguished librarians which was advising the Commission on Colleges and Universities on its procedures for the evaluation of libraries concluded that check lists of the type that had been employed should be abandoned. The committee explored alternative kinds of lists which might be used for accrediting purposes, but concluded that no type of list had been suggested which really got around the criticisms which had been leveled at the older lists. The North Central Association does not now use check lists in its evaluations of college libraries.

The next two criteria have to do with expenditures for books and salaries. The measures used in connection with these two items have undergone some modification, but they have remained statistical and involve the use of norms for four different groups of institutions. Thus, a given junior college would be compared in expenditures with other junior colleges holding membership in the association. Here, as in other statistical measures, the notion of absolute minima had been abandoned in the early thirties. An institution's standing depended on its rank in comparison with similar institutions. The rank is expressed in terms of percentiles; for example, an institution which is at the median would have a percentile rank of 50. Zero is the lowest rank and 100 is the highest rank. It should be noted that the norms on which these ranks are based are derived from actual data and not from decisions as to what would be ideal.

As the criteria for expenditures for books and expenditures for salaries have evolved they have become, respectively, the expenditure for the previous fiscal year per student for books, periodicals, binding, and rebinding; and the expenditure for the previous fiscal year per student for library salaries, including parttime workers and student assistants. In the application of these criteria, account is taken of the trend of expenditures in recent years. 
There are some obvious difficulties about expenditures per student. Who can say that the individual student is really the unit that determines how great the expenditures for library purposes should be? Is it true, for example, that a college of 500 students should spend twice as much for books and salaries as a college of 250 students? We have simply not had enough research in the field of librarianship to justify such an assumption.

Our next two library criteria concern student and faculty use of the library. Our commission has thought that this was one of the really important factors in the evaluation of a college library. The use of the library reflects clearly the degree to which the library is a functioning part of the educational program. It makes no difference how fine the facilities, how complete the holdings, how well trained the librarians, if the library is not used.

In this connection our examiners have been asked to scrutinize the methods employed by the library in encouraging student use, the adequacy of the number of reserve books, the accessibility to books through open stacks or otherwise, the availability of desks in the stack for students working on special problems, the announcement of books by displays and notices, and other means of promoting student interest. The examiners have studied the trend in the circulation statistics, including especially the average number of two-week loans per student. Some rough statistics have been available to the examiners for making a judgment on the latter point.

It should perhaps be said that in actual operation the examiners have had to give primary attention to the degree of awareness of the significance of student use and statistics bearing on it rather than to refined procedures for comparing actual use in one institution with use in others. As you know, there is great difficulty in securing comparable circulation statistics from institutions. For example, how can the statistics for an open-stack library possibly be made comparable with figures for a library having closed stacks or limited access to the stacks? In many institutions, especially urban colleges and universities, circulation statistics at best are incomplete because of the availability of other libraries to students.

In the area of faculty use, attention has been given to similar matters. Our examiners have inquired into the provisions for securing special library material needed by faculty members, for informing instructors of new publications in their fields, for notifying teachers of the receipt of new publications, for generous policies relating to faculty withdrawals, and for compiling data regarding the extent of faculty use. After looking at these features, an intelligent examiner can distinguish between a college or university library which is functioning as a vital part of an educational program and one which is seriously moribund, but the North Central Association admits it has not developed measures for arriving at any more than a very rough approximation of student and faculty use.

We hope that the library profession itself can undertake studies of student reading which would go far beyond anything that has yet been attempted. Institution after institution has grappled with this problem with little success. Better measures of student reading would give us an indication not only of the effectiveness of the library but also of the vitality of the whole instructional program. Probably student reading habits are as good an index as we could get of the probability that the students will continue to pursue important intellectual questions after they graduate from college. The results of some of the studies that have been made of the reading habits of college graduates are as serious an indictment of American higher education as one could possibly find. If we had more precise measures of student reading, they would enable us to undertake significant experiments in the promotion 
of student reading. At the present time, we have only the crudest notions of the amount and quality of reading done by college students.

The last library criterion of the North Central Association is called "Distribution of Holdings and Expenditures." In applying this criterion the examiner attempts to make a rough judgment as to the relationship between the library holdings in different subject-matter areas and the degree of curricular emphasis of the institution in these areas. If a college, for example, has a large number of students majoring in the social sciences, it would be expected that the amount of library holdings would reflect this curricular emphasis. Also, the budgetary procedure of the institution will be explored to make sure that the needs of the library are taken account of in the preparation of a budget and that there is a rational plan for allocating library funds to different purposes. The concern here is primarily with sound procedures and attitudes and not with precise formulas.

This brief outline gives you some idea of our methods, the limitations of these methods, and the large amount of unfinished business in library evaluation from the point of view of an accrediting agency.

From time to time officers and committees of the North Central Association have considered the possibility of criteria relating to size of library staff, professional education of librarians, proportion of educational and general expenditures that should be devoted to the library, the status of librarians in an institution, and other matters which are important in the development of effective library service. However, the problem of defining good practice in these matters without at the same time straitjacketing institutions and discouraging departures which might be desirable in individual institutions has been an obstacle to the development of policies. Also, an accrediting agency, as a representative body, has to proceed on the basis of reasonable consensus and is not in a position to adopt policies which are unsupported by convincing research or by what might be called the informed opinion of the academic profession.

If this picture of the present state of affairs in the evaluation of college libraries is reasonably accurate, and admittedly the description is somewhat disconcerting, what lines of thought seem most promising for the future? As already suggested, research on student reading habits in relation to instructional methods is a most promising field of inquiry. Such research, better than any other type of study, would dramatize the common interests of librarians and college teachers.

Are there other promising avenues? In this connection mention should be made of a mode of attack on the whole accrediting problem which is now being explored by a special committee of the Commission on Colleges and Universities. This is to abandon the time-honored practice of carving an institution up into discrete parts for purposes of analysissuch parts as purposes, faculty, curriculum, instruction, library, student personnel services, and administration-and basing the whole procedure of evaluation on certain central questions about an educational program. These would be big questions that would entail the gathering of data from many relevant sources. Such questions as the following would provide the guidelines for evaluation:

1. Does the institution have a clearly defined educational task? Under this consideration would be given to such items as definition of clientele, scope and character of the program, relationship to other institutions, and plans for the future.

2. Does the institution have the resources necessary to carry out its: purposes? This question invites attention to financial support, size and competence of faculty, library and other facilities for instruction, physical plant and site, and special considerations in a research institution. 
3. Is the institution well organized for the consideration of educational policy? Here the data would relate to the operation of the governing board, administrative leadership, faculty organization and stability, and provision for institutional studies.

4. Has the curriculum been carefully developed in the light of the institution's purposes? To answer this question one would have to look at the admission requirements, the provision for general education, the provision for specialized education, the incorporation of new knowledge in the curriculum, and the limitation of the offerings to courses which are really substantial.

5. Are the conditions of teaching satisfactory in this institution? This involves such matters as faculty personnel policies, teaching loads, class size in relation to field and teaching methods, syllabi and course organization, adaptation of methods to subject matter and student population, and student reactions to teaching.

6. Does the institution have a climate of serious intellectual interest? This is a difficult question to answer. Among the topics that might be included are: the student use of time; student retention; student reading (including use of the library); student understanding of the educational policies of the institution; educational experimentation in the institution; the vigor of student organizations in such fields as debating, journalism, dramatics, and religion; independent study by students; and scholarship program.

7. Is the student life well balanced and responsible? This would call for an examination of the conditions of student living, the maturity of student behavior, the scope of student participation in institutional government, student employment, the counseling program, student activities, the values reflected in student life, and similar matters.

8. Is there evidence that the level of educational achievement of the students is satisfactory? The answer to this would come from the results of tests; the proportion of graduates continuing their education; the academic records of graduates going on to higher institutions; studies of vocational, professional, religious, civic, and other achievements of graduates; quality of student papers, theses, and other types of performance; and institutional provisions for evaluation of student achievement.

Now, if such an approach is adopted, this would mean that the North Central Association would no longer consider the library in isolation as a separate agency in an institution, which is certainly a tendency where separate criteria are adopted for a college library, and would instead focus attention on large questions which more nearly cut across the whole life of the institution. Student reading would be considered, not as reflecting the effectiveness of the library alone, but as a manifestation of the total effectiveness of the institution.

Is this not a sound approach? Has the time not come to adjust the techniques of evaluation to the ideas we have been advocating on the unity of the educational process? From a practical point of view, this proposed approach has much value. It would give more point to much of the data-gathering that goes on in American higher education, both by professional organizations and by faculty committees engaged in self-studies. This may be something that the Junior College Library Section of the Association of College and Reference Libraries will wish to take into consideration at its earliest convenience. 